\title{
GÉNESIS E IDENTIDAD DEL GRUPO FUNDACIONAL DE LA ACN DE JP (1904-1909)
}

\author{
POR \\ PABLO SÁNCHEZ GARRIDO ${ }^{1}$ \\ Universidad San Pablo CEU. Madrid
}

\begin{abstract}
RESUMEN
El objetivo de este trabajo es estudiar la génesis de la histórica "Asociación Católico-Nacional de Jóvenes Propagandistas» (posteriormente, ACN de P) a partir de su gestación y preparación previa en la congregación madrileña de los "Luises» entre 1904 y 1909. Para ello, el texto se centra en su acción a través de su órgano de expresión, Hojas Sueltas, y en sus primeras conferencias públicas. Asimismo, se da a conocer la identidad del grupo fundacional de la ACN de JP, ya que los nombres completos y semblanzas del conjunto de estos miembros cofundadores eran prácticamente desconocidos. Finalmente, el texto aporta algunas conclusiones para clarificar la identidad ideológica del grupo.
\end{abstract}

PALABRAS CLAVE: catolicismo social español; «ACN de P»; congregaciones marianas; anticlericalismo; religiosidad pública.

\section{GENESIS AND IDENTITY OF «ACN DE JP»'S FOUNDATIONAL GROUP (1904-1909)}

\begin{abstract}
The aim of this essay is to study the genesis of the historical «Asociación Católico-Nacional de Jóvenes Propagandistas» (later, «ACN de $\mathrm{P}$ ») from its previous gestation and preparation in the congregation of «Luises» in Madrid, between 1904 and 1909 . So the article focuses on its action throughout the organ of expression -Hojas Sueltas- and others public meetings. Likewise, this essay has brought to light the identity of all the members of the foundational group of the ACN de JP, because the complete names and biographic notes of these cofounder members was unknown. Finally, the text points out some considerations about the ideological identity of the group.
\end{abstract}

KEY WORDS: Spanish social catolicism; «ACN de P»; anticlericalism; Marian congretations; public religiosity.

Cómo CITAR ESTE ARTículo / CITATION: Sánchez Garrido, P. 2017. «Génesis e identidad del grupo fundacional de la ACN de JP (1904-1909)». Hispania Sacra 69, 139: 389-400. doi: 10.3989/hs.2017.026

Recibido/Received 26-10-2014

\section{INTRODUCCIÓN Y CONTEXTO}

No poco se ha escrito sobre la repercusión de la Asociación Católica Nacional de Propagandistas (ACN de P), en la historia contemporánea de España y del movimiento católico español. Según afirmaba J. Andrés-Gallego: «Como es sabido, la Asociación Católica Nacional de Propagandistas (entonces, de Jóvenes Propagandistas) es una de las sociedades más importantes de la España contemporánea». ${ }^{2}$ Pero la dimensión más conocida de su historia es, con diferencia, posterior a aquella primera etapa fundacional

1 psanchez.ihum@ceu.es / ORCID iD: http://orcid.org/0000-0002 $-8720-9602$

2 Andrés-Gallego1993: 252-253. en la que todavía esgrimía su denominación originaria: "Asociación Católico-Nacional de Jóvenes Propagandistas» (ACN de JP). ${ }^{3}$ Esta primera etapa abarca desde la primera reunión fundacional de 1908, que después será analizada, hasta el momento en que, una vez constituida, pasó a denominarse ACN de P, perdiendo la «J» de jóvenes, hecho que ocurre hacia 1917.

Cuando la ACN de JP fue fundada por parte del jesuita Ángel Ayala, bajo el apoyo e impulso del nuncio de san Pío $\mathrm{X}$, Mons. Vico, estaba compuesta por dieciocho jóvenes

3 Una excepción es el artículo documental antes citado de José Andrés-Gallego y el primer volumen de la Historia de la ACN de P, realizado por José Luis Gutiérrez (2010), que han sido de gran utilidad para esta investigación, cuyos primeros pasos se remontan a 2007. 
y su primera actividad fue la de lanzarse a una campaña cuasi quijotesca de mítines de propaganda católico-social por toda España. Esta primera etapa ha quedado eclipsada historiográficamente bajo la trascendencia de momentos posteriores, mucho más célebres debido a la repercusión histórica de sus miembros y de las iniciativas sociales o políticas relacionadas con ella, como fueron la creación del Partido Social Popular o de la CEDA; de diarios como el $\mathrm{Ya}$; de instituciones culturales y foros socio-culturales, como el CEU, los Cursos de Verano del Colegio Cántabro de Santander, las Conversaciones Católicas Internacionales de San Sebastián, o las Conversaciones de Gredos; de instituciones sociales, como la Confederación Nacional Católico Agraria, el Instituto Social Obrero, o Cáritas; así como el "Grupo Tácito», ya en la Transición Española. Asimismo, esta primera etapa también ha quedado muy oscurecida debido a la precariedad documental derivada de la pérdida de los documentos archivísticos y de la ausencia de órganos propios de difusión. ${ }^{4}$

Hay otro hecho significativo que contribuyó a acometer esta investigación y es que si se observan los diversos listados de los miembros fundadores de la ACN de $\mathrm{P}$, ni siquiera se consignaba el nombre completo -o correcto- de todos ellos. ${ }^{5}$ En prácticamente todos los listados de sus fundadores a menudo se introducen errores de transcripción, como, por ejemplo: Luis "Castell» en vez de Castel; Rafael "Rotlland», en vez de Rotllán; José "Polanco», en vez de Palanco; Manuel «González Roldán», en vez de "Gómez-Roldán»... ${ }^{6}$ Pero, una vez que, en el contexto de este artículo, se logró identificar sus nombres completos, también resultó sumamente complejo hallar datos biográficos de muchos de ellos, excluyendo, lógicamente, al P. Ángel Ayala y a Ángel Herrera Oria, así como a algunos de los demás miembros que tuvieron una mayor relevancia política posterior, como es el caso de Lamamié de Clairac, Jaime Chicharro, José Manuel de Aristizábal, o José Palanco. Del resto de estos miembros fundadores no fue tarea sencilla ni siquiera conocer sus nombres y datos biográficos básicos, ya que varios murieron muy pronto, por lo que, además de la indagación hemerográfica y archivística a través de partidas de bautismo y defunción, testamentos, certificaciones académicas, etc., hubo que recurrir a la localización y

4 El archivo histórico de la ACN de P previo a 1936 fue destruido durante la Guerra Civil. El archivo de los Luises en Alcalá de Henares apenas conserva lo relativo a estos años. Los archivos de El Debate se perdieron tras la quiebra del diario Ya. Por otro lado, el Boletín oficial de la ACN de P comienza su andadura en 1924, cuando ya han muerto varios de ellos y a otros tantos les pierde la pista. El diario El Debate comienza su vinculación a la ACN de JP entre octubre y noviembre de 1911.

5 Entre los listados originarios, pueden destacarse el aportado por el P. Ángel Ayala (1999) en su obra Formación de selectos (1940), el del Boletín de la ACN de P [en adelante: BACNP]. 1-XII-1949: 446, referencias históricas de Ángel Herrera Oria en diversos lugares; o los listados de publicaciones vinculadas a la ACN de P, como la primera historia «oficial», que publicaron, en 1968, Isidoro Martín -por entonces Rector de la Universidad Complutense- y Nicolás González Ruiz (1968: 29-30). También, la primera biografía del P. Ayala escrita por un miembro de la ACN de P que le trató directamente, Cervera 2009 [1975]: 145-146. Obras historiográficas más recientes, como las de José Andrés Gallego, José M. a García Escudero o José Luis Gutiérrez, suelen remitirse igualmente a dichos listados por lo que a menudo reproducen las imprecisiones en los nombres de estas fuentes primarias.

6 Simón Tobalina y Rivera Blanc 1973: 13. consulta directa a sus descendientes. ${ }^{7}$ Incluso uno de ellos, Ventura Prieto, ha resultado imposible de identificar con su nombre completo al cabo de esta investigación.

Por tanto, ¿quiénes fueron los «jóvenes propagandistas» que contribuyeron a crear esta asociación civil y religiosa que estaría llamada a ejercer tan intensa influencia en la historia social, eclesial y política de la España del S. Xx? ¿Cómo lograron unos desconocidos congregantes universitarios desarrollar una asociación que en pocos años sería tan influyente en el mundo de la comunicación y de la cultura, de la política y de lo social?

En este texto, además de analizarse la identidad del grupo fundacional y de afrontar estas cuestiones, se procurará arrojar algo de luz sobre algunas nebulosas o imprecisiones relativas a los primeros años pre-fundacionales y a la génesis previa de esta histórica asociación socio-religiosa. Se deja para otro artículo, en continuidad con este, afrontar el análisis de los primeros mítines católico-sociales y actividades de la ACN de JP, a partir de 1909. Dilucidar aspectos sobre esta etapa de su génesis asociativa tiene un especial valor hermenéutico para comprender su evolución posterior, como ocurre con la génesis e identidad fundacional de cualquier institución histórica. También indicar que en la exposición y documentación de la mayor parte de las cuestiones analizadas en este artículo, se ha procurado no repetir las narraciones de hechos históricos que ya hayan sido expuestos en otros trabajos previos, remitiendo a ellos para su consulta, para centrarse este en aspectos inéditos o insuficientemente documentados históricamente. ${ }^{8}$

Pero, antes de responder a estas cuestiones, conviene ofrecer unas breves coordenadas contextuales que enmarquen el análisis posterior, principalmente desde dos hechos históricos que propiciaron la creación de la ACN de JP: el anticlericalismo, como factor externo, y la desunión y pasividad en la vida pública del catolicismo español, como factor ad intra. En términos políticos, la primera década del veinte fue un periodo de intensa inestabilidad, con gobiernos que duraban un año o unos meses -con la «excepción» del llamado "gobierno largo» de Maura, que logró llegar a los dos años y medio. Pero, en lo que respecta a nuestro tema, fue una etapa ciertamente caracterizada por una fuerte confrontación anticlerical. El auge del anticlericalismo a principios del S. $x x$ es un hecho manifiesto, que, sin entrar a evaluar sus causas, se desarrolló en diversos planos, que tendieron a retroalimentarse. Por un lado, puede destacarse el anticlericalismo popular, vinculado al auge entre las masas trabajadoras del socialismo, anarquismo y republicanismo radical; que estalló en los disturbios anticleralicales de

Aprovecho para agradecer la información aportada a todos los descendientes contactados en diversos momentos de esta investigación, concretamente a los descendientes (en su mayor parte hijos o sobrinos) de: Luis y José Manuel de Ariztizábal, M. Bofarull, Luis Castel, S. Cavengt, Juan Colomer, Jaime Chicharro, J. Fernández de Henestrosa, José M.a Lamamié de Clairac, Gerardo Requejo, Rafael Rotllán y J. M. a Sauras. En el "Archivo Histórico de la A. C. de P.», ubicado en la Universidad san Pablo CEU, hay muy escasa documentación de una mínima parte de ellos por su destrucción en la guerra civil.

8 Ello no ha sido óbice, lógicamente, para que se hayan recogido datos o narraciones ya publicadas allí donde la coherencia de la exposición lo haya requerido, lo cual también contribuye a aportar una síntesis de la bibliografía y de los datos dispersos sobre la cuestión analizada. 
la «Semana trágica» de 1909. Igualmente, desde el plano cultural experimentó notable incremento el anticlericalismo, cuyo hito paradigmático sería sin duda el estreno de Electra de Galdós -obra que pronto se convirtió en todo un símbolo anticlerical y que daría nombre incluso al «Gabinete Electra» de Sagasta-. En el sonado estreno de la obra, en 1901, el primer Maeztu gritaba: «iabajo los jesuitas!», que fue acompañado por otros gritos similares del público, como «iabajo los Luises!». Tanto los jesuitas como los Luises fueron los objetivos preferidos de los ataques anticlericales en los primeros años del s. xx. ${ }^{9}$ También desde la clase política, hubo diversos tipos y grados de anticlericalismo por parte de estadistas que lo apoyaron abiertamente, como Lerroux, Salmerón, Pablo Iglesias, Moret, o Canalejas. En el gobierno de este último, se retiró al embajador español en la Santa Sede, o se promovió la conocida como "Ley del Candado», contra la que la ACN de JP ejercería una contundente campaña que tuvo una fuerte repercusión social. ${ }^{10}$ Desde la prensa, el anticlericalismo también ejerció una fuerte presencia, fundamentalmente desde la prensa liberal y progresista, como la del famoso consorcio conocido como el "trust», ${ }^{11}$ o desde el beligerante enfoque de otros diarios como El Paíso Los Dominicales del Libre Pensamiento. Sin olvidar, El Motín, de José Nakens, que se convertiría en una especie de portavoz oficial del anticlericalismo más virulento. En el sector contrario, la prensa católica, o favorable a la Iglesia, estaba bastante limitada en cantidad y número de lectores, pudiendo destacarse: El Siglo Futuro, periódico nocedaliano de carácter integrista, El Correo Español, carlista, El Universo, o el entonces naciente $A B C$ fundado en 1903 como semanario y en 1905 como diario-. ${ }^{12}$

El otro problema que precipitó el nacimiento de la ACN de JP fue la cuestión de la desorganización social y desunión

9 Cfr. La Época, 31.I.1901, pp. 1-2. De hecho, en una de las algaradas posteriores al estreno se apedreó la sede de la congregación, se intentó asaltar bajo gritos de «iMueran los jesuitas!», o «iQuememos esa casa!»; cuando intentaron asaltar el edificio para entrar en la capilla, la policía reprimió la manifestación. cfr. El País, 9.Il.1901, p.2. Algunos meses después, Galdós atacaba a los Luises y a los jesuitas en su sonado artículo: «La España de hoy», Heraldo de Madrid, 9.IV.1901, p. 1 [publicado originalmente en Viena]. Véase, igualmente Madariaga de la Campa 1994. En sentido contrario, una representación de los Luises (presidente, secretario y bibliotecario) hizo una visita a Galdós en su casa (13.IV.1901), donde fueron recibidos con amabilidad por el novelista, que al parecer les reconoció que tan sólo les conocía por referencias. Cfr. El País, 1.V.1901, p. 3. Como no lograron una retractación pública del escritor, la Junta Directiva de los Luises envió una larga carta-artículo de réplica al artículo de Galdós (23.IV.1901), que fue reproducida y comentada en diversos periódicos.

10 En 1908, Lerroux fundó el Partido Radical y un par de años antes había escrito en su conocida arenga: «Jóvenes bárbaros de hoy, entrad a saco en la civilización decadente y miserable de este país sin ventura, destruid sus templos, acabad con sus dioses, alzad el velo a las novicias y elevadlas a la categoría de madres para virilizar la especie, penetrad en los registros de la propiedad y haced hogueras con sus papeles para que el pueblo purifique la infame organización social, entrad en los hogares humildes y levantad legiones de proletarios, para que el pueblo tiemble ante jueces despiertos». Lerroux 1906.

11 El "trust» era el nombre común de la empresa "Sociedad Editorial de España», creada en 1906, que unía a distintos periódicos progresistas, fundamentalmente: Heraldo de Madrid, El Liberal, o El Imparcial.

12 Aunque además de estos más generales, había una amplia proliferación de periódicos regionales y locales. Podría destacarse el caso de La Gaceta del Norte, madrina de El Debate de la ACN de JP. política de los católicos, cuestión que queda suficientemente constatada por los diversos documentos eclesiales y pontificios dirigidos a los católicos españoles ante esta doble problemática. Estos documentos, que influyeron notablemente en la configuración inicial de la ACN de JP, se inauguraron con la Cum multa (1882), por parte de León XIII, mientras que san Pío X, dedicó su carta «Inter catholicos hispaniae» (1906) o las «Normas pontificias a los católicos españoles» (1911) -comunicadas por Merry del Val al primado Aguirre-; sin olvidar las instrucciones a los católicos españoles (1908), difundidas por Mons. Vives. Pero hubo otros documentos que fueron cruciales en este tema, muy relacionados con los anteriores: se trata de los tres informes de Vico sobre la situación del catolicismo español, que elaboró entre 1890 y 1892, antes de su periodo como nuncio (1907-1912). ${ }^{13}$ Como un posible remedio a esta problemática endémica del catolicismo español, el nuncio de san Pío $X$ optó por impulsar el desarrollo la Acción Católica en España, comenzando por la rama juvenil (Juventud Católica), para lo cual apoyó la creación previa de la ACN de JP, como su posible órgano vertebrador. ${ }^{14}$ Como ha señalado J. L. Gutiérrez al respecto: «Fueron pues, la necesidad urgente, y, por ello, el propósito de organizar la Acción Católica en España, a la vista de los susodichos informes, los que pusieron en marcha la creación de los propagandistas». ${ }^{15}$

\section{GÉNESIS PREFUNDACIONAL DE LA ACN DE JP EN LOS LUISES E IDENTIDAD DEL GRUPO FUNDACIONAL}

Pasando ya al tema específico de la ACN de JP y sus antecedentes históricos, conviene comenzar por una precisión sobre la primera denominación de esta asociación. Sobre ella se han dado diversas versiones, a menudo incompletas o cuando menos inexactas. ${ }^{16}$ Pero, según consta en diversos documentos propios de la Asociación y en la propia prensa de la época, su nombre oficial fue, literalmente: "Asociación Católico-Nacional de Jóvenes Propagandistas» -con el guión incluido-. ${ }^{17}$

Sobre su nombre inicial, según un documento interno de 1939 donde se detalla su primera denominación:

Se discutió si había de llamarse "Juventud Católica", pero esta denominación parecía propensa a confusiones. Prevalecían dos ideas dominantes, características de la Obra, y que debían estar expresadas en su misma denominación, a saber, la propaganda católica y la propaganda nacional. De ello resultó el título "Asociación Católica Nacional de Jóvenes Propagandistas" [sic], un

13 Para ahondar en la visión del nuncio, impulsor la ACN de JP, sobre el catolicismo español, véase: Cárcel Ortí 1988 y 1992.

14 La organización de la Juventud Católica por la ACN de P se aplazó unos años, sobre este tema, véase Watanabe 2003.

15 Gutiérrez 2010: 33.

16 Siendo frecuente denominarla: «Asociación Católica Nacional de Jóvenes Propagandistas», pero también se ha nombrado eliminando "Católica» o «Nacional». Incluso, en confusión con otra organización eclesial, se la ha denominado: «Acción Católica Nacional de Jóvenes Propagandistas».

17 Así aparece en El Debate, órgano de la ACN de JP -a partir de noviembre de 1911-, así como en los estatutos, leyenda de la foto original de grupo en 1909, y en el pasquín publicitario del mitin de febrero de 1910, etc. Igualmente, en las diversas crónicas de prensa de ESF y en otras referencias coetáneas como Ferrer 1919. 
poco demasiado largo tal vez y que al correr de los años e ir dejando con ello de ser jóvenes muchos de sus miembros, se convirtió en "Asociación Católica Nacional de Propagandistas". ${ }^{18}$

En cuanto a la fecha en que la ACN de JP pierde su J de «jóvenes», es decir, cuando pasa a tomar la denominación con la que fue más conocida, a saber «Asociación Católica Nacional de Propagandistas» (ACN de P), hay cierta oscuridad al respecto, igualmente. En esa primera historia cuasi oficial de la ACN de JP -Seglares en la historia del catolicismo español- sus autores señalan la fecha de 1917. ${ }^{19}$ Por otro lado, en la publicación que hace El Debate de las primeras Asambleas deja de hablarse de los «jóvenes propagandistas» en la de $1916 .{ }^{20}$ En cualquier caso, no existe una fecha cierta sobre la que fundar este cambio de denominación pues se debió más bien al desuso por el natural envejecimiento de su primera generación. Esto explica que, por ejemplo, en un artículo-reportaje de 1919, todavía se pudiera hablar de ella en términos de "ACN de JP», ${ }^{21}$-téngase en cuenta que su autor tuvo que obtener de manos de la propia asociación una documentación tan detallada como la que expone-.

También ha habido cierta confusión sobre la fecha de fundación de la ACN de JP, pues, en cierto modo, hubo dos actos o momentos "fundacionales»: el de la primera reunión convocada por el P. Ayala, en noviembre de 1908, y el de la imposición de insignias por parte del nuncio Vico, en diciembre de 1909. Por ello, como se expondrá a continuación, creo que es más clarificador distinguir entre el momento constitutivo de la ACN de JP (1908) y su momento inaugural (1909).

Comenzando por el primero -el momento constitutivo-, se trata del acto por el que su fundador, el padre Ángel Ayala, convocó en el colegio de Areneros, aún en construcción, a un primer grupo de ocho miembros de la congregación mariana del Buen Consejo y de san Luis Gonzaga, conocida como «los Luises». ${ }^{22}$ En aquel entonces, el P. Ángel Ayala, que contaba cuarenta y un años, había dirigido aquella congregación mariana de los Luises entre 1903 y octubre de 1908, ya que el jesuita había llegado a Madrid en diciembre de 1903, después de ser ordenado en Sevilla unos meses antes. La etapa del P. Ayala al frente de los Luises -compuesta en su mayoría por universitarios- fue de renovación y revivificación de la congregación, que en ciertos aspectos había ido degenerando

18 «Breve noticia de su desenvolvimiento. La Asociación Católica Nacional de Propagandistas», Archivo Histórico ACdP, Febrero de 1939, p. 1, citado por Gutiérrez 2010: 15.

19 Martín y González Ruiz 1968: 83. Indican que desaparece la «J» de las convocatorias de "Círculos de Estudios y otros actos de la Asociación».

20 Quizá sea esta la referencia que utilizan I. Martín y N. González para señalar 1917 como el año en el que esta asociación abandona la «J) en su denominación original.

21 Cfr. Ferrer 1919: 347 y ss.

22 Para una historia de la congregación, véase López Pego 1999. Pero la obra apenas dedica unas frases a estas veladas-literarias, así como al órgano Hojas Sueltas, en que nos centraremos posteriormente, ya que según nos indicó personalmente el autor los archivos de estos años están perdidos y no pudo encontrar ningún ejemplar de Hojas Sueltas. Para conocer las «reglas comunes» de las congregaciones marianas que hizo el P. general Wernz en 1910, y otros rasgos, véase Anónimo 1927: 112 y ss. En ellas se insiste con especial énfasis en la importancia de las secciones de propaganda y en las academias. En cuanto a los fines, se alude a la perfección interior y al apostolado social. en un "casino recreativo» -en el decir de M. Revuelta-, 23 labor que acometió en tres frentes: la vida espiritual, la aplicación del método tan "ayaliano» de la selección y formación de jóvenes -Formación de selectos (1940) será una de sus obras fundamentales-, y el salto a la vida pública. ${ }^{24}$ Por su parte, Ángel Herrera ya estaba vinculado a los Luises y a su Academia de Derecho y Literatura durante su periodo en la Universidad de Deusto (1903-1906), de cuyas asociaciones fue directivo, junto con otros futuros propagandistas, como Lamamié de Clairac, Medina Togores, Sautu, etc.

Tras diversas referencias imprecisas a unna tarde de noviembre», o un "domingo de noviembre» -o incluso alguna confusión sobre la posibilidad de que ocurriera un 4 de noviembre de $1908-,{ }^{25}$ José Luis Gutiérrez aclaró que la fecha de la convocatoria tuvo que ser el 15 de noviembre, siguiendo la indicación de Francisco Cervera en su biografía sobre el P. Ayala de que este encuentro se produjo el «tercer domingo de noviembre de 1908 ". ${ }^{26}$

El jesuita Ángel Ayala convocó por carta a un grupo selecto de sus antiguos congregantes -téngase en cuenta que abandonó la dirección de los Luises un mes antes para ser el primer rector de ICAI- ${ }^{27}$ y se reunieron en la sala segunda del edificio del Colegio de Areneros y del naciente ICAI -hoy Universidad Pontificia de Comillas (ICADE-ICAI) en la madrileña calle de Alberto Aguilera, entonces calle de Areneros-. En un Boletín de la ACN de P de 1934, se narra del siguiente modo:

En 1908 el P. Ayala pasa al Colegio de Areneros y deja los Luises. Su idea sigue fija. Hay que despertar el espíritu católico español, que parece dormido. Un día escribe unas cartas. Avisa a un grupo de aquellos Luises predilectos y a otros jóvenes conocidos de Areneros. Uno a uno van llegando al Colegio. Son alrededor de una docena. No saben para qué se les llama, ni que han llamado a otros. Van coincidiendo en la segunda sala de visitas del colegio. ${ }^{28}$

¿Quiénes fueron estos jóvenes congregantes seleccionados por el P. Ayala? No se puede hacer aquí un seguimiento biográfico exhaustivo pero aportaré algunas pinceladas generales, excluyendo lógicamente a Ángel Herrera Oria y el P. Ángel Ayala por estar bien documentadas y difundidas sus biografías. ${ }^{29}$ El nombre completo de aquellos ocho primeros

${ }^{23}$ No obstante, el informe de nunciatura sobre los Luises, ya en 1896, era muy elogioso, cfr. Cárcel Ortí 1988: 929.

${ }^{24}$ Cfr. Revuelta 2008, II: 578. Sobre esto último, añade el autor que esto «era un primer ensayo para convertir a los congregantes en propagandistas», Ibídem.

25 Cfr. García Escudero 1998: 19; Orella 2012: 42; Revuelta 2008. El error se debe seguramente a una malinterpretación de un fragmento de la obra Seglares en la historia del catolicismo español (Martín Martínez y González Ruiz 1968: 29), donde tras la alusión a eventos ocurridos el 4 de noviembre se alude a continuación a esa tarde de domingo de 1908. Pero el 4 de noviembre de 1908 no fue domingo, ni el tercer domingo pudo haber sido un día 4. Para la explicación de esta confusión, véase: Gutiérrez 2010: 17. Para la referencia de Cervera 2009: 145.

26 Gutiérrez 2010: 17.

27 Pasar a ser rector de Areneros/ ICAI desde el 12 de octubre de 1908.

BACNP, 1934: 184: 1.

29 El resultado de estas investigaciones biográficas lo desarrollaré más extensamente en una monografía. Se incluyen estas semblanzas en nota al pie para no romper el hilo argumental del artículo. 
jóvenes es el siguiente: Luis de Aristizábal y Machón, ${ }^{30}$ Jaime Chicharro y Sánchez-Guío, ${ }^{31}$ José Fernández de Henestrosa y Escovedo, ${ }^{32}$ Manuel Gómez-Roldán y de Velo y Arce, ${ }^{33}$ Ángel Herrera Oria, José María Lamamié de Clairac y de la Colina, ${ }^{34}$

30 Madrid, 1.XI.1875 - 15.X.1954. Fue secretario de la congregación mariana de "los Luises» de Madrid, en la etapa del padre Ayala, hacia 1903. Participó en la fundación de la Editorial Católica y de El Debate, como secretario de Ángel Herrera y secretario de la Redacción de El Debate, hasta 1930 aproximadamente. En 1924 participa junto a otros miembros de la ACdP en la organización madrileña de la Juventud Católica Española. Tras la guerra civil se dedicó fundamentalmente a ejercicio de la abogacía y al cuidado de su familia; reservando sus ratos libres al cultivo de la escritura. Fue presidente de las Conferencias de San Vicente de Paúl. Era hermano del también socio fundador y futuro alcalde de Madrid José Manuel de Aristizábal.

31 Torralba de Calatrava (Ciudad Real), 22.VIII.1889-Guadarrama (Madrid), 13.I.1934. Nacido en una familia tradicionalista, fue educado en los jesuitas y posteriormente estudió Derecho en Deusto. Después estudia Filosofía y realiza el doctorado. Fue docente de Historia del colegio de los jesuitas en Madrid, y a su vez entra en contacto con el círculo tradicionalista de Vázquez de Mella, de quien fue secretario y discípulo. Se traslada a Castellón y funda Diario de Castellón y participa como redactor en La Gaceta de Levante. Es elegido diputado en varias ocasiones, en 1919 (mellista) y en 1920 (partido liberal-conservador de La Cierva), así como en 1933. En 1920 vuelve a Madrid, donde también es elegido concejal del Ayuntamiento durante la alcaldía de José Manuel de Aristizábal. Su matrimonio con Dolores Lamamié de Clairac le emparenta con el otro socio fundador, José M.a Lamamié de Clairac. Hay una biografía: Fandos 1961.

32 Madrid, 12.VIII.1886-Madrid, 27.IX.1936. Licenciado en Derecho por la Universidad Central en 1911. En 1912, se casó en Jaén con Isabel Sanmartín Contreras. Perteneció a las Congregación Mariana de «los Luises». Participó en diversos mítines de la ACN de JP, como el de Fuenteovejuna -lugar de estrechos vínculos familiares-, as como en el homenaje de la ACN de P a Ángel Herrera en 1914, junto a Gerardo Requejo, Rafael Rotllán y Manuel Gómez-Roldán. Murió fusilado por milicianos republicanos en Madrid, el día 27 de septiembre de 1936, junto a su hijo Francisco. La confirmación de su identidad, por existir otro familiar homónimo, y de su fallecimiento el 12.IX.1936, fue aportado en testimonio oral por su descendiente, Luis Fernández de Henestrosa Balmaseda el 8.X.2008 y por Gabriel Alonso Fernández de Henestrosa.

33 Madrid, 25.VII.1867-(fecha y lugar de fallecimiento desconocidos). Estudia en el Instituto cardenal Cisneros, obteniendo el bachiller en 1884. Licenciado en Derecho en la Universidad Central, en 1890. Fue presidente de los Luises hacia 1905. Además de fundador, fue secretario general de la ACN de $\mathrm{P}$ y miembro de su consejo nacional, aproximadamente entre 1912 y 1930 . Hacia 1926, fue teniente alcalde de Madrid y Concejal de Beneficencia, durante la alcaldía de José Manuel de Aristizábal, pero dimite en 1927 por problemas de salud. Miembro de la Comisión Organizadora de la Unión Patriótica, junto a J. M. Aristizábal. Presidente del Consejo de Administración de EDICA y EI Debate. Su rastro desaparece hacia 1935, fecha hacia la que quizá fallece por sus constantes problemas de salud y avanzada edad de 67 años.

34 Salamanca, 16.VIII.1887-27.IV.1956. Nació en el seno de una familia legitimista francesa que emigró a España y se vinculó al tradicionalismo. Estudió en los jesuitas de Valladolid y cursó Derecho en Deusto -examinándose en Salamanca- y en la Universidad Central de Madrid, obteniendo el título en 1909, e iniciando en Madrid los estudios de doctorado. Coincidió con Herrera tanto en el colegio como en la Universidad. Pero como narra en sus memorias Gil-Robles, Lamamié se separa pronto de la ACN de JP por considerar que no respondía a sus criterios integristas. En 1912, se trasladó a Salamanca donde ejerció la abogacía y se dedicó con notable y duradero éxito a la explotación agrícola y ganadera. Asimismo, desarrolló una intensa actividad en el campo de la política y en el de la acción social agraria. Consejero y presidente de la Federación Católico Agraria de Salamanca, de la Unión Católico-Agraria Castellano-Leonesa -que auspició la Confederación Hidrográfica del Duero, de la que fue vicepresidentey de la Confederación Nacional Católica Agraria. En lo político, militó
José Palanco Romero ${ }^{35}$ y Gerardo Requejo Velarde. ${ }^{36}$ Aunque el P. Ayala había sido el director de la congregación, su presidente o "prefecto» -cargo que, según los estatutos, recaía sobre un congregante seglar- era, por estos años, Manuel Gómez-Roldán, ${ }^{37}$ siendo sustituido algunos años después por

en las filas integristas, hasta que en 1931 volvieron a unirse con los carlistas. En Salamanca fue concejal de su Ayuntamiento durante cuatro años. Tras la Dictadura primorriverista organizó en el campo salmantino un movimiento socio-político llamado Acción Castellana. Con la República, se centró aun más en la acción política, llevando a las Cortes a los tres diputados que formaban el Bloque Agrario: José María Gil Robles -propagandista al que él mismo había empujado hacia la acción política-, Cándido Casanueva y él mismo. Más tarde, Gil Robles se separó de Lamamié de Clairac para fundar la CEDA. Como Diputado, hacia 1932, sus intervenciones se centraron en la defensa de la religión frente a las políticas laicistas y en la oposición a los proyectos de Reforma Agraria y del Estatuto Catalán. El Frente Popular anuló su acta en las elecciones de 1936, tras lo cual se volcó en una intensa campaña de propaganda tradicionalista por toda España, así como en la gestación del Alzamiento desde la organización del requeté. Al iniciarse el Alzamiento marchó a Pamplona y fue secretario de la Junta Nacional Carlista de Guerra. Después de la guerra se retiró de la vida pública volviendo a su ciudad natal.

35 Talavera de la Reina (Toledo), 7.IX.1887-Granada, 16.VIII.1936. Protagonizó el itinerario más peculiar del grupo, pues acabó ingresando en la masonería y en el partido republicano de Azaña, desde el que llegó a ser alcalde de Granada. Este viraje se produjo una vez asentado como catedrático de Historia en Granada, donde comenzó militando a favor del catolicismo social, como venía haciendo desde la ACN de JP. Pero algunos años después entró en una profunda crisis personal -su biógrafo sugiere que pudo influirle la muerte de su hijo Ricardo- que le hizo cambiar drásticamente sus planteamientos ideológicos. Palanco muere en Granada, fusilado el 16.VIII.1936 por los nacionales. Cfr. Gómez Oliver 2007. El autor de la biografía me indicó por correo que desconocía su pertenencia inicial a la ACN de JP, dato que no recoge, por tanto, en su trabajo. Por otro lado, en el material que preparó Ángel Herrera Oria para lo que serían sus memorias, después de aludir a que Palanco fue padrino de Fernando de los Ríos en la masonería, lo describe como «[...] un buen amigo mío, propagandista en su primera juventud, apóstata después, pero conciliado con la Iglesia al fin de su vida, murió edificantemente», "Memorias del cardenal Herrera Oria» (fragmentos), s.f., Archivo Ángel Herrera, Fundación Pablo VI, Texto B, p. 42 bis.

36 Madrid, 4.VI.1885-1952 (c.). Estudió leyes en Oviedo y Filosofía y Letras en Madrid. Hacia 1904 ingresa en la congregación mariana conocida como «los Luises», a la sazón dirigida por el P. Ángel Ayala SJ, de la que llegó a ser prefecto. Fue presidente de la Juventud Católica Española y de la Congregación de los Luises en Madrid. Varias fuentes coinciden en señalarse como gran orador, entre ellos A. Pidal y Mon. Dio junto a Herrera los primeros mítines de la ACN de JP y elaboraron juntos el primer editorial de El Debate del que fue cofundador. Fue director de la Revista Social y Agraria, órgano de la Confederación Nacional Católico Agraria, y de la revista Lectura Dominical. Como periodista, destacan sus artículos en El Debate, durante los años 10 y 20; y en diversos periódicos de la época, que en ocasiones firmaba con seudónimo. También destacó como escritor católico, con una serie de cuentos y novelas cortas publicadas en la década de los veinte. A finales de los 20 se traslada a Oviedo y Gijón, donde participa en periódicos y radios de la región (Voluntad, Radio Gijón...). En sus años de vejez sufrió una crisis que le llevó a mendigar en la calle. Muere internado por su familia en un geriátrico de Madrid.

37 En noviembre de 1904, ya participa en el Congreso hispanoamericano de congregaciones marianas como redactor de una memoria (La Cruz, 26.XI.1904 pp.1-2), pero aparece explícitamente firmando por los Luises la carta colectiva que se entregó y leyó en audiencia ante el rey en contra de la ley de asociaciones, La Correspondencia de España, 15.XII.1906. En 1912, se sigue aludiendo a él como «prefecto», El norte, 9.IV.1912. 
Gerardo Requejo; el secretario fue Luis de Aristizábal, ${ }^{38}$ mientras que su tesorero fue José M. a Sauras. ${ }^{39}$ Herrera apenas aparece en escena durante estos años previos a 1909 porque llegó a Madrid hacia junio de 1906 donde continuó sus estudios de Filosofía y Letras e inició los de doctorado, después de concluir los de Derecho en Deusto (1905) -examinándose en Salamanca-. Pero en 1907 se puso a preparar las oposiciones a abogado del Estado, que gana en febrero de 1908, tras lo cual permanece siete meses destinado en Burgos, para regresar a Madrid en octubre de 1908, tan solo un mes antes de la reunión constitutiva en Areneros. ${ }^{40}$

A lo largo de 1909, el jesuita fue seleccionando a otros congregantes de los Luises hasta conformar el grupo de los 18 primeros jóvenes propagandistas, cuya incorporación quedó formalizada tras el solemne acto inaugural de la ACN de JP, el 3 de diciembre de 1909, en la iglesia de la Inmaculada y san Pedro Claver -la iglesia de ICAI, que se inauguraba aquel mismo día-. Los otros «jóvenes propagandistas» que se unieron a los ocho iniciales en ese día de san Francisco Javier, fueron: José Manuel de Aristizábal y Machón ${ }^{41}$ (hermano menor de Luis), Manuel de Bofarull y Romañá, ${ }^{42}$ Luis Cas-

38 Aparece como secretario de los Luises ya en enero de 1904, aunque en esta fecha figura como presidente de los Luises: Emilio M. de Torres. Cfr. La Época, 8.I.1904, p. 2.

39 Cfr. Fernández Areal 1970; López Pego 1999: 79-80. En la prensa también se alude a Gómez-Roldán como presidente, por ejemplo, ESF 28.I.1908, p. 3.

40 Pidió la excedencia en 10.X.1908 para continuar con los estudios de Filosofía y Letras en Madrid. La Vanguardia Española, 18.IX.1966 p. 6 y 1.VIII.1968, p. 6 . He trabajado toda la etapa inicial de Herrera en el artículo: «Genealogía intelectual de Ángel Herrera», Aportes, 2016.

${ }^{41}$ Madrid, 26.VIII.1882 - 6.II.1950. Licenciado en Derecho en la Universidad Central de Madrid (ca. 1898). Dos años después defendió su tesis doctoral: El Matrimonio según los principios de la ley natural. En la ACN de P, fue consejero presidencial de la Asociación desde los primeros años de la Asociación hasta 1927, aproximadamente. En 1926, ocupó la presidencia en funciones de la ACdP durante la XIII Asamblea General, por la ausencia de Ángel Herrera. En la Unión Patriótica madrileña destacó su colaboración como Vicepresidente de la Sección de fomento de Madrid, hacia marzo de 1927. Su hermano Gabriel era el secretario general de la Unión Patriótica de Madrid. En la CNCA ostentó importantes cargos directivos, como Presidente de la Federación Agrícola Mirobrigense, Vicetesorero y Presidente de la CNCA desde junio de 1927. El 20.XII.1927 sería nombrado alcalde Presidente de Madrid por elección, pero en julio de 1929 presentó su dimisión como alcalde, esta vez por desavenencias con el ministro de gobernación, ante lo cual el mismo general Primo de Rivera instó por escrito público al Ayuntamiento a rechazar su dimisión, por lo que concluye su mandato en febrero de 1930. Fue diputado provincial en 1924 y miembro de la Asamblea Nacional Consultiva en 1927 y en 1928. Con la República, volvió al ámbito directivo de la CNCA, ocupando otros cargos de relevancia como el de Vicepresidente. Al inicio de la Guerra Civil, fue encarcelado por los republicanos durante cuatro meses acusado de «desafección al Régimen». Después de lograr la liberación, fijó su residencia en Ciudad Rodrigo, donde además de sus labores profesionales, llevó a cabo una intensa acción social y de compromiso religioso.

42 Madrid, 1887 - 6-I-1974. De familia carlista, se licenció en Derecho con Premio Extraordinario en 1908. En 1910, Bofarull concluyó su tesis doctoral titulada La representación pública en España, también con Premio Extraordinario. Fue abogado en ejercicio desde 1909. En 1916, fue elegido académico profesor de la Real Academia de Jurisprudencia y Legislación y numerario en 1947. Desde 1924 a 1928 fue concejal del Ayuntamiento de Madrid. También desempeñó los cargos de consejero delegado del Canal de Isabel II. Representante del Ayuntamiento de Barcelona en Madrid. Presidente de la Junta de Gobierno del Monte de Piedad y Caja de Ahorros, desde 1944 fue Vicepresidente de su Caja de Ahorros. Procurador en Cortes en 1952. tel y González de Amezúa, ${ }^{43}$ Santiago Cavengt Gutiérrez, ${ }^{44}$ Andrés de Montalvo y Gómez-Hermosa, ${ }^{45}$ Rafael Rotllán Molina, ${ }^{46}$ José María Sauras Navarro, ${ }^{47}$ Mateo de la Villa y

Tuvo una participación fundacional en El Debate y la Editorial Católica (EDICA), de la que fue miembro de la Junta de gobierno hasta su muerte. Fue vocal del Consejo de las Corporaciones Católico-Obreras e igualmente del Banco Popular de León XIII, del que llegó a ser gerente. Fue miembro fundador del mítico Grupo de la Democracia Cristiana, junto a Severino Aznar. Fue autor de un abundante número de publicaciones jurídicas, como Las antiguas Cortes, el moderno Parlamento, y el régimen representativo orgánico (1916 y 1945), y editó las obras de Vázquez de Mella. Mantuvo siempre su relación con Herrera y la ACN de P.

43 Madrid, 31.VII.1885 - 31.XII.1914. Abogado de profesión. Era hijo de Carlos Castel y Clemente, un hombre de ciencia y miembro de la Real Academia de Ciencias Naturales. Su pronto fallecimiento por una meningitis, tan solo cinco años después de haberse fundado la ACN de JP, redujo su posibilidad de participar activamente en la misma. Sin embargo, además de participar en el «mitin monstruo» de 1910 y en otros mítines, en el Archivo del Congreso de los Diputados queda constancia de su participación en junio de 1911 ante el Senado, donde argumentó como "informante» su oposición a la "Ley del Candado», impulsada por Canalejas. En 1913, leyó ante el Presidente del Consejo de Ministros, Romanones, un documento de protesta por parte de organizaciones estudiantiles católicas. Fallece en 1914 con veintinueve años.

44 Madrid, 26.XI.1883 - 12.XII.1969. Fue una importante figura de la medicina y uno de los pioneros de la pediatría española. Estudió Medicina en la Universidad Central en 1908, donde leyó su tesis doctoral en 1910. Algunos años más tarde llegaría a ser Jefe Clínico de Pediatría de la misma Facultad. En 1911 es nombrado médico supernumerario de la Beneficencia Municipal de Madrid. Su vinculación profesional más relevante fue con el Hospital del Niño Jesús, en Madrid, donde desarrolló casi toda su carrera, ejerciendo en ella, como Jefe del Servicio de Pediatría y Decano del Hospital. Publicó gran parte de sus trabajos en la revista La Pediatría Española, órgano de dicho Hospital, que más tarde dirigiría. Se especializó en medicina pediátrica. Endocrinología infantil (1922) será una de sus principales obras, prologada por el mismo Gregorio Marañón. En 1943, funda y dirige Acta Pediátrica, junto con el también acenepista Juan Bosch Marín. En 1958 dimite de su cargo directivo en el Hospital del Niño Jesús, aunque siguió vinculado de modo honorario.

45 Santander, 11.IV.1881-Madrid, 24-X-1914. Su padre fue alcalde de Santander. Cursó sus estudios de Bachiller en Valladolid y se matriculó en la Facultad de Filosofía y Letras de la Universidad Central a los dieciséis años, que compagina con la carrera de Derecho. Defendió dos tesis doctorales en la Universidad Central, una en Historia, titulada Estado social y político de Castilla durante el reinado de Fernando III el Santo (1904), y otra en Derecho, con el título La ley y sus caracteres según la doctrina de Santo Tomás (1906). En la ACN de JP fue su primer secretario general. Presidió el multitudinario mitin de octubre de 1910 en el Jai Alai. Además de terciario dominico, fue vicepresidente de los Luises, miembro del Ateneo de Madrid y Caballero de la Orden de Montesa. Obtuvo la cruz de Alfonso XII. Fallece a los 33 años. Identificación a partir de la fecha de fallecimiento del Catálogo general de la ACN de P, Madrid, 1930, p. 75 y de la partida de defunción del Registro Civil e información en el AHN.

46 Lebrija (Sevilla), 6.VII.1878-Madrid, 29.III.1922. Estudió bachillerato con los padres jesuitas en Puerto de Santa María y después se licenció en Filosofía, sección Historia, con los jesuitas de Granada (noviciado de la Compañía). Fue periodista, fundamentalmente crítico de arte, de El Debate, y antes en El Siglo Futuro, siendo Redactor Jefe de ambos periódicos. Para El Debate escribió anónimamente diversos artículos de fondo y editoriales, según se reconoce en la necrológica que le hace el periódico. ED 1.4.1922. Agradezco la partida de bautismo aportada por su descendiente Francisco Rotllán Vaca. Identificación a partir de la fecha de fallecimiento del Catálogo general de la ACN de $P$, Madrid, 1930, p. 75 y de la partida de defunción del Registro Civil e información en el AHN.

47 Zaragoza, 28.XII.1878 - Campo del Ángel (Alcalá de Henares), 30.XII.1970. Obtiene el Bachiller en Zaragoza, en 1896. Se traslada a Madrid donde cursa Filosofía y Letras, y algunas materias en la Universidad de Valencia. Ingresó por oposición en el Banco de España, 
Sanz. ${ }^{48}$ Juan Colomer Beneito ${ }^{49}$ también es introducido por la propia tradición asociativa de la ACN de JP en el elenco de propagandistas fundadores del año 1909, como hace el segundo presidente, Fernando Martín Sánchez, ${ }^{50}$ el P. Ayala y como reconoce el propio Colomer. ${ }^{51}$ Como se dijo anteriormente, no ha sido posible identificar a Ventura Prieto. ${ }^{52}$

¿Cómo se seleccionaron? Según explica el P. Ayala: «Por sus aptitudes oratorias, su talento y por su espíritu»..$^{53}$ Lo que consta en cualquier caso es que al menos con este grupo

en el que se jubilaría como Subcajero de Valores. Tras su estancia en Valencia, donde parece que ejerció su primer destino profesional, regresa a Madrid, e ingresa en la congregación de los Luises, de la que sería su Tesorero. Fue cofundador algunos años más tarde de la Editorial Católica y del diario El Debate, del que llegaría a ser su primer administrador. En 1928 participa en la comisión de la ACN de P que envió a la Asamblea Nacional un proyecto de Estatuto de Prensa. Durante la Guerra Civil fue detenido a causa de su vinculación con la Editorial Católica y El Debate y condenado por desafección a dos años y seis meses en diversas cárceles de Madrid, Alicante y Orihuela; siendo liberado en febrero de 1939. Se ordenó sacerdote a los setenta y seis años, siendo el hecho noticia internacional. Para ello contó con la preparación previa de su viejo amigo Ángel Herrera, ya obispo de Málaga, de quien recibiría las órdenes menores. La ordenación fue en el Colegio de los jesuitas de Madrid, en abril de 1955, siendo oficiada por el obispo auxiliar de D. Ángel Herrera, Mons. Benavent. Fue capellán de EDICA y del YA.

48 Aranjuez (Madrid), 1891 (circa)- Madrid, 19.VIII.1922. Abogado de profesión. En junio de 1911 participó como informante oral ante el Senado en la oposición que se suscitó frente a la llamada «Ley del Candado» de Canalejas. En esta labor de oposición, figuró junto a casi todos sus compañeros propagandistas de la primera promoción. Asimismo, participó como orador en las campañas de difusión del sindicalismo católico agrario, en el seno de la Confederación Nacional Católico Agraria. En noviembre de 1916 fue nombrado juez en Belmonte (Cuenca). Falleció, aun soltero, a la edad de treinta y un años, a causa de una uremia. Identificación a partir de la fecha de fallecimiento del Catálogo general de la ACN de P, Madrid, 1930, p. 75 y de la partida de defunción del Registro Civil.

49 Juan Blas Colomer Beneito, Bocairente (Valencia), 1880 (circa)¿Alicante?, 25.X.1964. Inició los estudios de Medicina que no puede concluir por razones familiares por lo que se dedicó a la profesión de agente comercial. Aunque estuvo presente en el acto fundacional de 1909, tuvo que marcharse antes de la imposición de insignias, por lo que la recibió en 1924. Primer Gerente de El Debate. Secretario cofundador del Centro de Sevilla de la ACdP hacia 1912, donde fue presidente de la Juventud Católica. Participó en la directiva madrileña de la Unión Patriótica. Jefe de sección en la Federación Católico agraria valenciana. Se incluye en la relación del P. Ayala en la biografía de F. Cervera, así como en el primer BACNP de 1924. Hay una necrológica de Juan Colomer en BACNP, 797, abril (1965), p. 4.

50 Cfr. Martín-Sánchez 2002: 420 y 807.

51 En su expediente del archivo histórico de la A.C. de P., hay una nota de Alfredo López a Sagüés pidiendo que se rectifique el error de no considerársele miembro fundador por no aparecer en la foto de grupo de 1909, ya que, según transcribe del interesado: «...no pude yo figurar por haber tenido que ausentarme al terminar el acto religioso para atender un asunto urgente de alguna importancia». Archivo Histórico ACDP, expediente de Juan Colomer Beneito. Le fue impuesta la insignia en la segunda imposición, el 11.V.1924, aunque en el Boletín figura como fecha de su ingreso el 15.X.1909.

52 Solamente se ha encontrado su participación en la inauguración en 1914 de la iglesia de la Concepción de Madrid, La Correspondencia de España, 12.V.1914, p. 3; o su intervención en 1916 en la inauguración de la «Academia Social» de la Congregación de los Luises de Madrid. En ella defendió la acción social católica y afirmó que «los jóvenes católicos practican la democracia cristiana y en ella se inspiran», ED, 26.I.1916. Una posible identidad sería la de Ventura Prieto Anca, posteriormente médico rural, pero no se ha podido confirmar.

53 Ayala 1999: 294. escogido de congregantes, el P. Ayala desarrolló un intenso adiestramiento, fundamentalmente centrado en la oratoria oral y escrita, que acabó convirtiendo a este grupo escogido de Luises en el "vivero» de la ACN de JP. Según especifica el propio jesuita: «La formación primera se redujo: a ejercicios de composición oratoria, declamación, discusión, crítica literaria ${ }^{54}$ Más adelante, precisa:

Se les ejercitó en la declamación, aprovechándose hasta de la escénica. Se les adiestró en la discusión pública, en ejercicios literarios, en crítica artística. Se repitieron los ejercicios cuando se pudo, públicos y privados. Se hizo recaer la actuación siempre sobre los mismos sujetos. El plan fue preparar selectos para el apostolado público. Pero no hubo ni plan social, ni religioso, ni menos político, que no podía haberlo. ${ }^{55}$

De este modo, el P. Ayala había tenido oportunidad de conocerlos y ponerlos a prueba durante su etapa como director de la congregación mariana durante cinco años. Al cabo de los cuales casi todos habían participado, juntos o por separado, en varios actos públicos de la Congregación antes de aquella reunión constitutiva de noviembre de 1908.

\section{DE CONGREGANTES A PROPAGANDISTAS: PRIMERAS ACTIVIDADES PÚBLICAS EN LOS LUISES (1904-1908)}

Dos actividades fueron las que vehicularon ad extra este adiestramiento: las "veladas literarias» y el semanario Hojas sueltas, que explicaré con cierto detalle porque estas nos dan razón tanto de la génesis del grupo inicial, como de sus primeras actividades públicas, que desembocaron en los posteriores mítines social-católicos y en el desarrollo del diario El Debate, ya como miembros de la ACN de JP.

Comenzaré describiendo algunos casos ilustrativos de las actividades públicas fundamentales durante estos años: las «veladas literarias» o "literario-musicales». Estas eran convocadas por el P. Ayala con los Luises en el salón-teatro de la congregación para sufragar los gastos de los dos patronatos de ayuda social que tenía la congregación: el Patronato de jóvenes obreros y el Patronato de barrenderos. ${ }^{56}$ Constaban, por lo general, de una conferencia de temática socioreligiosa, junto a ella se intercalaban en diversos momentos de la velada la interpretación de piezas de música clásica y la declamación o interpretación de fragmentos literarios de poesía, novela o teatro, fundamentalmente de autores españoles (Cervantes, Pereda, Alarcón, Ramón de la Cruz, Gabriel y Galán, etc.); para continuar con una sección de "discusión», en la que se debatía una cuestión social o religiosa, con una exposición general y su posterior réplica

54 Ayala 1999: 292.

55 Ídem.

56 Cfr. Cervera 2009: 127 y ss. Además de sufragar las becas formativas, los jóvenes congregantes, realizaban otras labores con los obreros miembros de ambos Patronatos, como clases nocturnas, acompañamiento y formación religiosa, etc. Para sufragar estas ayudas se ofrecían estas veladas públicas a los benefactores, que se suscribían a ellas anualmente pues se desarrollaban a lo largo del curso académico; o bien pagaban la entrada. ESF, 2.XII.1907, p. 2. El amplio salón de actos con escenario, platea y palcos estaba en la sede de la Congregación, junto a la residencia del P. Ayala, en la calle Zorrilla 1,3 y 5. La sede de los Luises con las amplias aulas, salón de actos y sala de billar, fue fundada en 1896 y costeada por la condesa de Rivadedeva. Cfr. López Pego 1999: 45-46. 
o comentario por parte de otros participantes. Un rasgo peculiar de estas veladas es que a menudo las conferencias se acompañaban de proyecciones de imágenes e incluso del empleo del cinematógrafo para ilustrar las exposiciones -nótese que nos encontramos entre 1904 y 1909 y que la primera exhibición del cinematógrafo Lumière en España fue en $1896-{ }^{57}$

La primera de las veladas que ejemplificaré, por su temprana cronología, es una velada en la fiesta de la Inmaculada Concepción del año 1904, en la que junto a la declamación de poesías (Gabriel y Galán) y la interpretación por otros congregantes de piezas musicales clásicas (Beethoven), se introdujeron diversas conferencias, como la de Luis de Aristizábal, con una conferencia bajo el tema: «El buen ejemplo en la vida privada es el fundamento de todo influjo social cristiano», junto a otra de Manuel GómezRoldán, sobre la cuestión: «El Apostolado de la Prensa más provechoso y fácil para las Congregaciones Marianas, consiste en la publicación y difusión de hojas populares»; tema que anticipaba la publicación de Hojas Sueltas, que lanzarían los congregantes dos años después, y a la que me referiré a continuación. ${ }^{58}$ Como segundo ejemplo, ya en un momento de mayor repercusión del grupo, El Siglo Futuro (en adelante ESF) recoge la participación, el 11 de febrero de 1908, de estos futuros propagandistas en otra velada literario-musical con una conferencia sobre "Las Madres», en la que figuran buena parte de los futuros «jóvenes propagandistas», con la asistencia del nuncio -en este año se trataba ya de Mons. Vico- y el Obispo de Astorga. En su primera parte tomaron la palabra: José Fernández de Henestrosa, Luis Castel y Gerardo Requejo. A continuación, en la sección «discusión parlamentaria», trataron sobre $E I$ feminismo: Gómez-Roldán, Aristizábal, Montalvo, Cavegnt, Castel, Requejo, Fernández de Henestrosa, Palanco, junto a otros -que ya no serían propagandistas fundadores-. ${ }^{59}$

57 En ocasiones, la finalidad de la proyección cinematográfica era meramente lúdica: "Unas cuantas películas de cinematógrafo, muy divertidas, completaron la agradabilísima velada de los Luises...», ESF, 5.I.1909, p. 3.

58 ESF, 10.XII.1904, p. 2. Por otro lado, cuando Ayala hablaba de que se les formó en la oratoria "escénica» no exagera pues también participaban en veladas literario-musicales en las que se representaba alguna obra teatral, como Los hombres de bien, de Manuel Tamayo y Baus, en la que Ángel Herrera realizó la lectura dramática y el «análisis literario", mientras que en el reparto figuraron Gerardo Requejo y José Fernández de Henestrosa. ESF, 13.XII.1906, p. 3. Otra velada, dedicada a Cervantes, se celebró el 15.V.1905, con la participación de Gómez-Roldán. La Época, 18.V.1905, p. 2. En la velada de Pascua del 26.XII.1906, entre los congregantes que actuaron estaba Requejo, siendo el acto presidido por el nuncio, el arzobispo de Valencia y e Provincial de Toledo. ESF, 27.XII.1906, p. 2. Asimismo, hubo otra el 30 del mismo mes y otra el 3 de enero de 1907, ESF, 24.XII.1907, p. 2. También el 15.V.1907, con un discurso sobre el gobierno de Sancho Panza, de Henestrosa y declamación cervantina por Requejo, entre otros. ESF, 15.V.1907, p. 2

59 Como Olózaga, Olavide, Cremades, etc. ESF, 10.II.1908, p. 3. Otra velada en la que participa Luis Castel, con una conferencia sobre los beneficios para el pobre de la escuela católica. Tras varios intermedios musicales (Gounod, Malats), hubo un debate de Montalvo, Requejo y Henestrosa y una conferencia de Gómez-Roldán. Las conferencias se acompañaron de proyecciones fotográficas y cinematográficas. ESF 30.IV.1907, p. 2. También el 27.I.1908, se celebró otra con la intervención de Requejo ("La acción social del congregante»), Henestrosa y Palanco -aunque se anunció a Castel- (debate sobre «El teatro contemporáneo»), Gómez-Roldán («Marruecos», conferencia
Esta velada, en la que el P. Ayala hizo desfilar a casi todos los futuros «jóvenes propagandistas» ante el nuncio Vico, demuestra que el intenso apoyo posterior de éste en la fundación la ACN de JP estaba basado en un conocimiento directo de aquellos «jóvenes propagandistas» a los que un año después les impondría las primeras insignias. El nuncio Vico vio en ellos a los jóvenes que podrían articular en España la futura Acción Católica.

En cuanto a la preparación y «primeras armas» en la propaganda escrita, es destacable la participación de estos congregantes en el órgano de expresión de la sección de propaganda de la congregación, publicación que, como se ha dicho, llevaba por título Hojas sueltas. Se trataba de unas hojas semanales de propaganda católica que lanzó el P. Ayala y en las que participaron sus congregantes escogidos y futuros propagandistas. Según expuso Requejo en una de las veladas de 1908: "En tres obras ha concretado, hasta el presente, la Congregación sus loables propósitos: el Patronato, la catequesis y el semanario Hojas Sueltas». ${ }^{60}$ Apareció este semanario hacia mediados de $1906^{61}$ y se editaba en la tipografía del Noticiero extremeño, de Badajoz, aunque su administración figuraba en la calle Zorrilla 5 y 7 de Madrid, sede de la congregación de los Luises y residencia del P. Ayala, pasando después a la calle Areneros. ${ }^{62}$ Parece que estas breves "Hojas Sueltas» de cuartilla crecida en dos páginas, alcanzaron una apreciable tirada anual (2.735.000, en 1907) y una amplia distribución por diversas regiones españolas -a través de suscripción e incluso de la entrega

con proyecciones). ESF, 25 y 28.I.1908, p. 2. Otra velada es la del domingo 28.IV.1907, en la que Castel dio un discurso sobre "Los niños pobres», tras la audición de Schuman y Saint-Saës, se abrió una "discusión» expuesta por Montalvo sobre "La prensa rotativa anticlerical», con Requejo, Henestrosa como «argumentantes» y una «conferencia social» sobre «jardines obreros» de Gómez-Roldán (con proyecciones). ESF, 27.IV.1907, p. 2. La del 3 de mayo de 1908 estuvo dedicada al Centenario de la Guerra de la Independencia, con un discurso de Chicharro, ESF, 4.V.1908, p. 2. Las del 26.XII.1908 no tuvieron conferencias, ESF, 22.XII.1908, p. 2. Para la del 4.I.1909, con participación de Henestrosa, véase ESF, 5.V.1909, p. 3; también el anuncio de otra en el $E S F, 27.1 .1909$, p. 3. En los anuncios de las veladas de febrero (18), abril (30) y mayo (4) de 1909 ya no se detalla el programa y la información se limita a un escueto párrafo, mengua quizá motivada por el hecho de que sus principales ponentes ya actuaban por entonces desde la ACN de JP. ESF solía anunciar las veladas y su programa con anterioridad al acto, pero el 28.I.1908 y 12.II.1908, se hace una amplia y apologética crónica en primera página lo que da muestra de una creciente relevancia en 1908, hasta casi convertirse en una sección del periódico el encabezado esporádico: «En los Luises».

60 ESF, 28.I.1908, p. 1

61 La hormiga de oro, no 31, agosto de 1906, p. 14. No confundir con otra publicación homónima publicada en Cáceres a partir de 1934.

62 No hemos podido encontrar la colección en ninguna biblioteca, como tampoco el historiador de los Luises, Carlos López Pego SJ, pero el dato de la tipografía procede del único ejemplar que hemos podido encontrar reproducido (2.IV.1908, no 116). Para este análisis de la revista se ha recurrido además a su eco en la prensa de la época y a los testimonios de algunos de su redactores, como el propagandista fundador, José M. a Sauras, quien afirma que esta se editaba en los talleres de un familiar del P. Ayala en Badajoz. Se refiere seguramente a Eduardo Ayala y Alarcó, hermano del P. Ayala y amigo de José Marín, propietario del Noticiero extremeño, lo cual además explicaría el protagonismo que este diario concedió al mitin pionero de la ACN de JP en Badajoz (28.III.1909). Ambos, apoyaron posteriormente el proyecto del P. Ayala de fundar o comprar un diario católico, ya en 1908; véase la correspondencia en el Archivo Secreto Vaticano, cfr. Conde (ed.) 2011: 103 y ss. 
o venta directa en calles y domicilios a través de la red de los Luises-. ${ }^{63}$ En cualquier caso, alcanzaron una importancia interna indudable como primera acción conjunta de los futuros propagandistas fundadores, dato que se deriva de los testimonios sobre esta publicación de varios de ellos, pero también del cierto eco social y mediático alcanzado. ${ }^{64}$ En este sentido, ha sido considerada igualmente como un precedente o embrión de El Debate. ${ }^{65}$ En cuanto a su contenido, la publicación constaba de artículos anónimos de temática más bien satírica, a veces con cierto tono humorístico -visible en su propia viñeta caricaturesca de cabecera-, frente a políticos (como Canalejas, Romanones...) y periódicos (como Heraldo de Madrid, El País, El Liberal...), considerados anticlericales. ${ }^{66}$ Además, en la sección «El Club», se incluían novelas y cuentos por entregas, como $E l$ rasero de don Lesmes, de Adolfo Clavarana, o Don Gonzalo González de la Gonzalera, de José M. a Pereda. ${ }^{67}$

Una acción más «agitadora» del grupo fue la campaña de boicot contra los periódicos anticlericales desarrollada entre 1908 y 1909, promovida desde Hojas Sueltas, desde la que se instó a los lectores católicos a no comprar los diarios que hubieran recibido condenas de anticlericalismo por parte de los obispos españoles. Pero lo peculiar de esta campaña, fue la introducción del uso de postales contra

63 Los beneficios de las suscripciones iban destinados al Centro Diocesano de la Buena Prensa y podían ser de una, media o un cuarto de acción que conllevaban respectivamente 400, 200, o 100 ejemplares, costando el centenar de ejemplares 3 céntimos y el millar una peseta. Para el dato de la tirada, carta del P. Ayala a Wernz (23. IV.1908), Cfr. Revuelta 2008: 579.

64 Habla de ella el socio fundador Manuel Gómez-Roldán en el acto conmemorativo de la fundación de la ACN de P en 1929, aludiendo a su naturaleza de órgano de expresión de la congregación. Gómez-Roldán, BACNP n.95 (1930), p. 1. El testimonio de José M.a Sauras es introducido por Cervera 2009: 128.

65 Cfr. López Pego 1999: 79; Revuelta 2008: 579.

66 En un breve de El País, titulado "Ardides de los frailes», hay una queja de esta publicación lamentándose de que el gobierno permita "circular toda clase de impresos, por muy indignos que sean» y que se permita su venta a domicilio por parte de frailes, mientras que se prohíbe a los mendigos pedir caridad en las casas. A propósito de ello, se dice: "Unos frailes reparten unas hojas clandestina, con unos cuantos artículos anónimos, completamente chocarreros é imbéciles, con injuriosas calumnias para empresas periodísticas, dignas de res peto, y con sus toques sicalípticos [sic] para dar gusto á los señores, y estas hojas circulan libremente, y sirven de gancho para sacar dinero a los incautos», El País, 4.III.1907, p. 2. La confrontación iba en ambas direcciones pues según se recoge en La Lectura dominical: «Lemos en Hojas Sueltas que El País publicó un escrito acusando á las Hermanas de la Caridad de que habían dejado morir un enfermo sin darle más que agua, á pesar de que con voz lamentable pedía caldos y medicinas», frente a lo cual Hojas sueltas publicó una carta firmada por otros enfermos de la misma sala del hospital que declararon bajo juramento que aquello era falso, tras lo cual se invitaba a El País a su rectificación. La Lectura dominical concluye: "No sabemos si ha rectificado, pero se deduce de lo expuesto que El país sigue en progresión descendente hacia el infierno", no 735, 1.II.1908, p. 13. El País vuelve a criticar Hojas Sueltas en 8.II.1909, p. 5.

67 Es significativo el enfrentamiento que se produjo entre los Luises y los carlistas en enero de 1904, que llevó a la expulsión de un grupo de carlistas de los Luises madrileños por su protesta violenta contra una representación teatral irreverente. Al parecer, mientras eran expulsados, algunos Luises afirmaron que preferían ser antes socialistas que carlistas. El tema tuvo repercusión en la prensa, como, por ejemplo, ESF, El correo español, que en esta ocasión atacaron a los Luises a favor de los carlistas; o El Imparcial, 17.I.1904, p. 2. También la prensa anticlerical se hizo eco del enfrentamiento. los rotativos anticlericales y la puesta a la venta de unas colecciones de sellos de caucho contra estos diarios, donde se podía leer, por ejemplo: «El Imparcial ha sido condenado por 19 obispos», e incluía textos similares contra El Liberal, Heraldo de Madrid, etc. ${ }^{68}$ En un artículo del diario anticlerical El Motín, tras jactarse satíricamente su autor de haber sido "excomulgado» [sic] por 47 obispos -posiblemente se trate de José Nakens-, se reproduce el texto de una de estas Hojas, donde sus autores detallaban los tres «pecados mortales» en que, según las Hojas, incurrían los católicos que leyeran dicha prensa: cooperación al mal, perversión y escándalo. ${ }^{69}$

De la fecha de estos artículos y campañas de Hojas sueltas, se deduce que este semanario seguía existiendo a principios de 1909, una vez que la ACN de JP ya había sido fundada, ante lo que cabe preguntarse sobre su relación posterior respecto a los «jóvenes propagandistas», o sobre si estos estaban actuando en paralelo como propagandistas y como Luises. ${ }^{70}$ La respuesta la encontramos en La Época, donde se afirma:

La publicación católica popular Hojas sueltas pasará en breve á ser órgano de la Asociación católica de Jóvenes propagandistas, que se propone iniciar una serie de meetings, por provincias, de propaganda social. Irán á las capitales, pueblos y aldeas, á dar conferencias sociales, y tomarán muy á su cargo favorecer á la Prensa católica. En la semana próxima se verificarán en Badajoz y Ciudad Real los primeros meetings sociales. ${ }^{71}$

Es curioso que este anuncio se haga una semana antes del primer mitin de la ACN de JP en marzo de 1909, ya que fue este su primer acto público, pero después de estos mítines no hemos encontrado referencias a nuevos números de Hojas sueltas, ${ }^{72}$ por lo que posiblemente dejó de existir y no llegó finalmente a convertirse en el órgano de la ACN de JP.

Parece que aunque las Hojas no alcanzaron ni lejanamente el estatus de un diario, ni en forma, ni en fondo, sin embargo, además de servir como entrenamiento para los «jóvenes propagandistas» que un par de años después iban a dirigir exitosamente el diario El Debate, sirvieron igualmente para el objetivo de alcanzar una cierta repercusión social en la propaganda pública católica, como se deduce de las críticas crecientes en la prensa contraria. ${ }^{73}$

68 Estos sellos estaban pensados para estamparse sobre cartas, sobres, o paquetes y se vendían a 6 y 10 reales desde la sede de Hojas Sueltas, -que ya había pasado de Zorrilla a Alberto Aguilera- ESF, 9.I.1909, p. 3.

69 El motín, 21.I.1909, p. 2; también se hace una fuerte crítica en La Verdad: semanario republicano, 31.X.1909, p. 2.

70 A título individual varios de ellos siguieron manteniendo el vínculo con ambas instituciones, como vemos en Gómez-Roldán, a la sazón presidente de los Luises en 1910.

71 La Época, 25. III.1909, p. 3.

72 ESF habla de una suscripción el 14.XII.1909, p. 2, pero por el contexto no se puede confirmar que siguiera publicando nuevos ejemplares en esa fecha.

73 Además de las anteriores referencias desde El País, o El Motín, en El Liberal hay un poema satírico contra la prensa clerical y se menciona «Hojas sueltas», 25.II.1909, p. 3. En un artículo sobre el auge del reciente auge de actividades anticlericales en España, al aludir a sus causas se dice: «A la acción anticlerical pertenece por sus efectos esta bárbara hojita que los jesuitas han repartido el día de Viernes Santo en la iglesia de Santo Domingo de Murcia» y a continuación se detalla 
Aunque las Hojas eran anónimas, su vinculación con los futuros propagandistas es clara, a partir, por ejemplo, de los testimonios de los dos socios fundadores antes referidos -Sauras y Gómez-Roldán-. A su vez, entre el 21 y el 24 de septiembre de 1908, varios de ellos, en concreto: Montalvo, Palanco, Bofarull y Gómez-Roldán, participaron en la II Asamblea Nacional de la Buena Prensa, celebrada en Zaragoza, en representación de la Congregación madrileña de los Luises y de su órgano semanal, Hojas Sueltas. ${ }^{74}$ En dicha Asamblea, Gómez-Roldán defendió la creación de «Ligas de compradores católicos», para boicotear económicamente la "mala prensa» a través de ligas locales federadas en juntas directivas. ${ }^{75}$ Palanco propone el programa que ellos mismos venían desarrollando: 1으, publicación de hojas semanales populares; 2ㅇ, actos literarios privados en Academias de Letras para entrenar periodísticamente a sus miembros; 3으, actos literarios públicos, «cuyo plan sea el desarrollo de un periódico, desde el artículo de fondo hasta los anuncios, sin omitir el folletín, las noticias y los telegramas»; y 4으, certámenes literarios. ${ }^{76}$ Montalvo se centró en el programa de Hojas sueltas y en su campaña de boicot postal a la prensa condenada por los prelados. ${ }^{77}$ El futuro propagandista David Fernández Diéguez: «propone la creación de una Escuela de periodismo católico» y de círculos-laboratorios de labor periodística, así como la elaboración de «un Manual o Tratado del periodista católico». ${ }^{78}$

Todo lo anterior nos sirve de enlace entre la actividad que desarrollaron como Luises y como «jóvenes propagandistas» pues se puede observar cómo la actividad en el entorno de los Luises les sirvió de plataforma de lanzamiento y de entrenamiento para la propaganda católica oral y escrita. Pero también les sirvió de red de contacto una vez que comenzaron su actividad en los mítines como ACN de JP, como demuestra el hecho de que en el momento de su llegada a Granada y a Sevilla, en el contexto de los mítines inaugurales de diciembre de 1909, fueran recibidos respectivamente por el director y por la Junta Directiva de los Luises y que varios de estos fueran los que formaron el primer grupo sevillano de propagandistas. ${ }^{79}$ Puede decirse que en diversos lugares, como Madrid, Sevilla, o más tarde Valencia, la ACN de JP se convirtió en una continuación natural de los congregantes, al menos de aquellos de mayor aptitud y vocación para lo público. ${ }^{80} \mathrm{El}$ itinerario: congregaciones marianas-ACN de JP, o algo más tarde, congregaciones-Acción Católica-ACN de $P$, fue el itinerario habitual de muchos de sus miembros durante décadas.

críticamente su campaña sobre los diarios condenados por los obispos, El País, 28.III.1909, p. 1 y 2. No obstante, su aparición en dichos diarios no deja de ser esporádica y de una atención relativamente escasa.

${ }_{74}$ Cfr. VV. AA. 1909: 418-419.

75 Ibídem: 258-259.

76 Ibídem: 305.

77 El programa consiste en la publicación de Hojas sueltas y en el boicot postal a través de tarjetas postales, sellos de "cautchout» (sic), papel de cartas y carteles, donde se denuncien los periódicos condenados por los obispos, así como elaborar un álbum de caricaturas con testimonios anticlericales de dichos periódicos. Ibídem: 234

78 Ibídem: 294-5.

79 ESF 19.XII.1909, p. 1.

80 El caso valenciano sería un ejemplo en este sentido, con el P. Conejos como alter ego del P. Ayala.
En cualquier caso, estas primeras actividades demuestran que los congregantes que finalmente integrarían el grupo final de los 18 propagandistas fundadores en 1909, ya se conocían previamente y que estaban participando igualmente en actividades públicas de la congregación, por lo que, seguramente, los otros diez congregantes que se unieron a los ocho primeros que convocó el P. Ayala en 1908, fueron incorporados por el P. Ayala a lo largo de 1909. Los hechos narrados también demuestran, como ya se ha dicho, que el nuncio conocía directamente a los propagandistas antes de apoyar su creación y sus primeras actividades.

\section{CONSIDERACIONES FINALES SOBRE LA IDENTIDAD IDEOLÓGICA DE LA PRIMERA ACN DE JP}

En las páginas anteriores ha quedado dibujada la identidad y las actividades prefundacionales del grupo de propagandistas que a partir de su acto constitutivo de 1908, se lanzaría a intensas campañas de mítines católico-sociales prácticamente en toda España. La finalidad originaria del grupo fue nítidamente católico-social, como lo fueron sus primeros mítines. ${ }^{81}$ Solamente en el año 1910, los «jóvenes propagandistas» dieron más de un centenar de estos mítines. De este modo, a principios de 1911, la ACN de JP ya contaba con una cincuentena de propagandistas y con 11 centros locales en Madrid, Sevilla, Huelva, Cádiz, Granada, Badajoz, Valladolid, Vitoria, Bilbao, Murcia y Palencia.

Pero, junto a esta identidad en lo social de la ACN de $J P$, ¿cuál fue su orientación en el plano ideológico-político? Según afirmaba el provincial de los jesuitas, el P. Valera, a fecha de comienzos de 1911 sólo había «[...] 3 integristas y 10 carlistas: los 37 restantes son independientes: y entre ellos ninguno es Jefe; sólo hay varios secretarios».82 El contexto de esta carta referida fue el incidente que se zanjó con el traslado del P. Ayala a Ciudad Real, a instancias del Obispo de Madrid, Salvador y Barrera, y del propio rey Alfonso XIII. Este último llegó a acusar al P. Ayala de haber «[...] inspirado y aconsejado al nuncio la formación de un partido católico que resulta verdaderamente antidinástico contra las Normas Pontificias», ante lo cual el Marqués de Comillas, le transmite al General de la Compañía de Jesús, Pedro Bianchi, que: «S.M. el Rey verá con mucho agrado que el Rmo. P. General de la Compañía, con la mayor reserva posible, y sin que se trasluzca el motivo aleje de Madrid a dichos Padres, y los destine adonde no puedan influir como hasta aquí en el ánimo del nuncio». ${ }^{83}$ José Andrés-Gallego dio a conocer la jugosa documentación epistolar que hubo detrás de todo este incidente y José Luis Gutiérrez lo ha glosado suficientemente; además, será objeto de otro estudio posterior sobre la ACN de JP en sus primeros

81 El artículo 1 del reglamento de la ACN de JP dice: «El fin de esta asociación es la propaganda católico-social», en Andrés-Gallego 1993: 294. Como ha afirmado en otro lugar Andrés-Gallego, J.: «[...] éste y no otro ( «la propaganda católico-social») sería el fin estatutario inicial de la Asociación Católico-Nacional de Jóvenes Propagandistas, que el Jesuita Ángel Ayala constituyó en 1909 [...]», Andrés-Gallego 1975: 358-359.

82 José M. a Valera SJ, "Documento sobre el P. Ángel Ayala S. J.», respondiendo a los cargos hechos por el obispo de Madrid. Manuscrito en el Archivium Romanum Societatis lesu, (ARSI) Tolet, leg. 1.003, carp. IV], Citado por Andrés-Gallego, J. 1993, p. 292.

83 Andrés-Gallego 1995: 409. 
años. ${ }^{84}$ En cualquier caso, aunque es cierto que contuvo entre sus filas algunos elementos integristas ${ }^{85}$ y tradicionalistas o carlistas, ${ }^{86}$ la documentación publicada por Andrés-Gallego deja claro que estos fueron minoritarios y que los políticos integristas miraban con recelo a los jóvenes propagandistas y al P. Ayala, como afirma el provincial de los jesuitas y reconoce bajo juramento el propio Ayala. ${ }^{87}$

Aunque no puede negarse que la ACN de JP tuvo un carácter antiliberal-sobre todo frente al liberalismo económico y frente a los aspectos más laicistas del liberalismo político español del momento-, este era un rasgo común a todo el primer catolicismo social español y no específico del integrismo, como ha demostrado Feliciano Montero. ${ }^{88}$ Por otro lado, desde sus comienzos, la ACN de JP fue asumiendo las consignas pontificias de León XIII, que derivarían en la posición del «accidentalismo» de las formas de gobierno y de un «posibilismo» hacia el bien común, lo cual supuso un distanciamiento de los católicos más integristas, como ejemplifica el caso de la baja del fundador José M. Lamamié de Clairac, ${ }^{89}$ o la relación que, desde el amor al odio, pasó a tener El Siglo Futuro hacia la ACN de P y hacia EI Debate..$^{90}$ Esta actitud de apertura, sin renunciar a la tradición cristiana quedaban confirmadas, en el ámbito católico-social, con el constante apoyo que la ACN de JP prestó al «Grupo de la Democracia Cristiana» de Severino Aznar -del que fue cofundador, por ejemplo, el propagandista fundador Manuel de Bofarull-. ${ }^{91}$

${ }^{84}$ Pero solo apuntaré que los protagonistas fueron el obispo de Madrid, el nuncio Vico, el Provincial de los Jesuitas de Castilla, y el general de los Jesuitas. A raíz del caso, la documentación epistolar incorporaba la primera propuesta de Estatutos de la ACN de JP, una declaración jurada del P. Ayala reconociendo la naturaleza apolítica y no integrista de la ACN de JP, una defensa del P. Valera, etc.

${ }_{85}$ Seguramente uno de estos jóvenes integristas era Rafael Rotllán, quien el 6 de noviembre 1910 participa en una velada de presentación de la Juventud Integrista de Madrid, aunque lo hace como miembro de la ACN de JP. Téngase en cuenta también que Rotllán fue redactor del diario integrista EI Siglo Futuro, hasta que la ACN de JP se hizo con El Debate. ESF 7.XI.1910, p. 1.

86 Lamamié de Clairac fue un destacado carlista, así como Chicharro, aunque éste se movió entre el mellismo y el cervismo.

87 Cfr. Andrés-Gallego, J. 1993. Ibídem, 288 y 292, «Declaración del P. Ayala», en ARSI. Citado por Andrés-Gallego, J. Ibídem, 296.

88 Cfr. Montero 2007: 106 y ss.

89 Es muy significativa en este sentido su salida de la ACN de JP, que nos narra José M.a Gil Robles a propósito de su propia vinculación a la ACN de P: «Llegué a Madrid desde Salamanca bastante prevenido contra ella por algunas amistades de mi familia inspiradas por absurdos criterios integristas, que continuaban frecuentando nuestra casa después de la muerte de mi padre. Procuró influir de manera especial sobre mí la familia presidida nominalmente por don Juan Lamamié de Clairac, cuyo hijo, José María, había sido uno de los ocho "Luises" a quienes citó el Padre Ayala en el Colegio de Areneros para proponerles fundar la Asociación. Pero cuando en 1911 Ángel Herrera, otro de los jóvenes fundadores y primer presidente de la misma ocupó la dirección de El Debate, imprimiéndole un rumbo que los lectores de El Siglo Futuro juzgaron "liberal", los elementos tradicionalistas -por lo menos, José María Lamamié de Clairac- se dieron de baja en la Asociación por considerarse punto menos que traicionados», Gil Robles 1975: 69-70.

90 Sobre el apoyo inicial a la ACN de JP en ESF: «EL SIGLO FUTURO ha asistido con júbilo al nacimiento de la Asociación, ha presenciado y dado noticia de sus trabajos y ofrece sus columnas para cuanto sea darles publicidad y extender por la difusión y propaganda la eficacia de sus trabajos.» ESF, 3.XII.1909. p. 2.

91 Aunque El Debate les reprochó en alguna ocasión lo innecesariamente comprometedora y equívoca que podía ser la denominación escogida por el Grupo.
Por otro lado, la ACN de JP fue desarrollando en paralelo con este accidentalismo y posibilismo otro de sus fines constitutivos: el de la unión de los católicos, como había pedido León XIII en la Cum multa, y san Pío X en su carta Inter catholicos hispaniae (1906); así como en las "autorizadas instrucciones a los católicos españoles» (1908) -firmada por el cardenal Vives, pero puede entenderse que "autorizadas» por san Pío X-, y por las Normas pontificias a los católicos españoles (1911) -comunicada por Merry del Val al primado Aguirre-. En todas estas normas promovidas en última instancia por san Pío $X$, un papa nada sospechoso de modernismo, se buscaba la unión de los católicos en materia social y política, a la par que se venía a desautorizar la posición maximalista del catolicismo más integrista y a autorizar la opción de un partido liberal, como podía ser el maurista, especialmente en las Normas de $1911 .^{92}$ En el propio «Reglamento» original de la ACN de JP -fechado según J. L. Gutiérrez en 1909-, el artículo 11, afirma: «Los propagandistas podrán pertenecer a cualquier partido político, pero deben conservar su libertad de acción y de voto en la forma señalada en las Normas de la Santa Sede a los católicos españoles». ${ }^{93}$ Incluso se ha afirmado que las normas pontificias de 1911 pudieron estar parcialmente suscitadas por Ángel Herrera tras su visita a san Pío X. Como afirma Andrés-Gallego en este sentido:

Sin olvidar que era este entonces aún un grupo naciente, tal vez fue sintomático que una de las consultas aludidas que motivaron tales reglas del año 11 había sido formulada por la Asociación Católica Nacional de Propagandistas. En la primavera, José María de Urquijo había enviado a Roma a un miembro destacado de la A.C.N. de P. (Ángel Herrera Oria un joven abogado estatal) y a dos representantes de aquella Junta de Vizcaya organizadora de las manifestaciones de 1910 (Epalza y Garmendia) a fin de pedir a la Santa Sede orientación "para sus propagandas futuras". Y Merry del Val les "ofreció el envío próximo de unas normas que ayudasen a esclarecer las principales cuestiones que entre nuestros católicos se planteaban". ${ }^{94}$

La ACN de JP y El Debate acabaron convirtiendo el tema de la «unión de los católicos» en torno a un "programa mínimo» en uno de sus reivindicaciones más intensas, sobre todo a partir de $1913 .{ }^{95}$

De hecho, mientras que para algunos, ya en los propios años fundacionales, pensaban que la ACN de JP estaba constituida por católicos antidinásticos, para otros fue vista como una asociación de católicos más bien cercanos a un conservadurismo liberal maurista y dispuestos a ceder a diversas "modernizaciones», tanto en lo social,

92 De la preocupación constante de Herrera por este tema habla la anécdota narrada por José M.a Sánchez de Muniaín de que, según le había confesado él mismo, Herrera rezaba por la unión de los católicos desde su adolescencia (Gutiérrez 2010: 143).

93 Gutiérrez 2010: 76.

94 Andrés-Gallego 1975: 414. Cárcel Ortí señala que Ángel Herrera había comunicado al cardenal Aguirre las instrucciones que le había dado Merry del Val en Roma para que la acción católica española se sometiera a la autoridad del cardenal Aguirre para evitar divisiones (Cárcel Ortí 1989: 325). Confirma el motivo del viaje a Roma como encargo de Urquijo el propio Herrera, en La Gaceta del Norte, 24.XI.1962. Fue trascendental el apoyo de Urquijo a la naciente ACN de JP, véase, al respecto, la excelente biografía de Cristóbal Robles (1997).

95 Gutiérrez 2010: 141 y ss. García Escudero 1983. 
como en lo político. ${ }^{96}$ Pero en realidad no fue ni una cosa ni otra. Lo que seguramente indujo a estas oscilaciones interpretativas respecto a su identidad es que uno de sus objetivos constitutivos fue precisamente ese intento, harto complejo, de lograr la «unión de los católicos»-tan escindidos y enfrentados entre sí en la España de entoncesasí como la aplicación incipiente del «accidentalismo» y del "posibilismo», que pronto se convertirían en señas características del grupo, con Herrera a la cabeza, sobre la base de una firme adhesión al respectivo magisterio pontificio. Años más tarde, en el cincuentenario de la Editorial Católica, Herrera se declararía contrario a la funesta división de las dos España y abogaría por la necesidad de su superación a través de una "Tercera España» en la que reconocía a autores como Jovellanos, Cánovas o Menéndez Pelayo y a la que él mismo se consideraba vinculado. ${ }^{97}$

\section{BibLIOGRAFÍA}

Andrés-Gallego, J. 1975. La política religiosa en España, 1889-1913. Madrid: Editora Nacional.

Andrés-Gallego, J. 1993. «Sobre los orígenes de los Propagandistas, ICAl y El Debate». Hispania Sacra 45: 249-306.

Andrés-Gallego, J. 1995. "La intervención de Alfonso XIII frente Ángel Ayala y los propagandistas». Hispania Sacra 47: 405-419.

Anónimo 1927: Las congregaciones marianas de jóvenes y adultos, firmado por "Un director de congregación". Barcelona, Luis Gili.

Ayala, Á. 1999. «Formación de selectos», en Obras completas, Vol. I. Madrid: BAC.

Cárcel Ortí, V. 1989. «San Pío X, los jesuitas y los integristas españoles». Archivium Historiae Pontificiae 27: 249-355.

Cárcel Ortí, V. 1992. «Instrucciones de Merry del Val a Vico en 1907 y relación final del nuncio en 1912», Revista española de derecho canónico 133: 567-605.

Cervera, F. 2009 [primera edición 1975]. Ángel Ayala. Madrid: CEU Ediciones.

Conde, F. (ed.) 2011. La ACdP, sus hombres y sus obras en el Archivo Secreto Vaticano (1908-1939). Madrid: CEU Eds.

Fandos Mingarro, P. 1961. Biografía de Jaime Chicharro: Madrid: AGEM.
Fernández Areal, M. 1970. La política católica en España: Barcelona: Dopesa.

Ferrer, M. 1919. "La Asociación Católico-Nacional de Jóvenes Propagandistas». Revista Católica de Cuestiones Sociales 300: 347-352.

García Escudero, J. M. 1998. Ángel Herrera. De periodista a cardenal. Madrid: BAC.

Gil Robles, J. M. 1975. La fe a través de mi vida. Bilbao: Desclée de Brouwer.

Gómez Oliver, M. 2007. José Palanco Romero. La pasión por la res pública: Granada: Universidad de Granada.

Gutiérrez García, J. L. 2010. Historia de la AC de P, vol. I. Madrid: CEU Ediciones.

Herrera Oria, Á.1963. Obras selectas. Madrid: BAC.

Lerroux, A. 1906. "Jóvenes bárbaros de hoy», en Rebeldes, rebeldes. Barcelona.

López Pego, C. 1999. La Congregación de "Los Luises" de Madrid: Bilbao: Descleé de Brouwer.

Madariaga de la Campa, B. 1994. "Galdós contra los Luises y los Luises contra Galdós», en Galdós en la hoguera: 87-106: Santander Tantín Ediciones.

Martín Martínez, I. y González Ruiz, N. 1968. Seglares en la historia del catolicismo español: Madrid: Raycar.

Martín-Sánchez, F. 2002. Ideas Claras, Madrid, BAC.

Montero, F. 2007. "Las derechas y el catolicismo español: Del integrismo al socialcristianismo». Historia y Política 18: 101-128.

Orella, J. L. 2012. El origen del primer catolicismo social español. Tesis doctoral de Derecho Político. Madrid: UNED.

Revuelta, M. 2008. La Compañía de Jesús en la España Contemporánea, vol. II. Madrid: UPCO.

Robles, C. 1997. Sánchez Garrido, P. 2016. «Genealogía intelectual de Ángel Herrera (1886-1908)», Aportes, 90: 29-63. J. M. $\underline{\underline{a}}$ Urquijo e Ybarra, Madrid: CSIC.

Sánchez Garrido, P. 2016. "Genealogía intelectual de Ángel Herrera (1886-1908)». Aportes, 90: 29-63.

Simón Tobalina, J. L. y Rivera Blanc, J. L. 1973. Asociación Católica de Propagandistas: Madrid, Bruño.

VV. AA. 1909. Crónica de la Segunda Asamblea Nacional de la Buena Prensa, Zaragoza: Tip. Escar.

Watanabe, Ch. 2003. Confesionalidad católica y militancia política: la ACN de $P$ y la Juventud Católica Española (1923-1936). Madrid: UNED.

96 Esta afirmación de que «...la Asociación de Jóvenes Propagandistas es... iconservadora!... iestá al servicio de Maura!» la refuta El Debate a tan solo unos días de haber adquirido el diario Herrera y sus socios. ED, 20.X.1911.

97 Herrera Oria 1963: 230-1 Madrid: BAC. La noción de «Tercera España», aplicada a los descontentos de ambos bandos en la Guerra Civil, ha sido atribuida a Salvador de Madariaga y a otros intelectuales como Alcalá Zamora y Alfredo Mendizábal -quien fuera en su propagandista y amigo de Herrera Oria-. 